\title{
Index rerum
}

actuarius $\quad 107-8,111,320$

Agon $45,71,100,102,128,133,135,138,146$, $157,161,168,187,208-11,296,314,358-$ 60

Akklamationen 42, 88, 91, 95-96, 131-33, $135,148,169,175-79,183-85,197,204$, 216, 218, 223-26, 228, 240, 309, 314, $322-26,333,355,378$

Akrobatik $14,170-71,187,210,236,249$, $258,263,266,279-82,293-95,305$, $335,346,361,366,379,381$

Alytarchie $71,85,103,135-36$

Antilope $210,264,269,272-73,276,280$

archimimus $\quad 44,123,311,353$

Asiarchie 72, 85, 103, 132, 154, 157, 257

Asket (siehe Mönch)

Athletentum 1, 45, 152, 208, 210-11, 26263, 329

Awaren 185, 271

Bär $98,239,250,258,264,267,271-73$, $276,278-79,286,381$

Bildnis (siehe Statue)

Bischof $31,34-36,39-42,50,65,69,71$, $77-78,102,116,126,144,164,176,191$, 221, 237, 285, 289, 307-8, 308, 314, 316, $327,332,345,370,387-89,393$

Boxer 153, 191, 211, 236, 264

boule (siehe Stadtrat)

Brumalia 129, 140, 158, 392

Brytae $67,102,158,321,364$

Circus Maximus $1,13,42,129,161-63,167-$ $68,180,196,199,201,212,218,232,252$, $259,276,284$

civilitas $172-73$

Claqueure $42,148,323-24$

Consualia 158

Contomonobolon 280

cornicularius $107-8,111,320$

curialis (siehe Stadtrat)

damnatio ad bestias $232,234,239,255,259$, 262, 270, 274

damnatio ad ludum 232, 234-36

Dekurionen (siehe Stadtrat)

Diptychon $115,130,174,187,189,227,265$, $269-71,279-80,347,361$ diversium 207, 214

Eber 250, 264, 279, 283, 286

Elch 278

Elefant 259, 261, 271, 278-79, 281

Entsakralisierung $33,35,55-58,61,337,377$, 395

Epigramm (siehe Gedicht)

epulae 56, 114, 125, 393

Exkommunikation $26,44,65,75,78,116$, 223, 248, 357-58, 370

Exotik $188,250,258,260-62,264,266,268$, 271, 278-286, 288, 379

Fans $147-49,154,198,210,214,216,218$, $267,329,380$

Fastenzeit 63, 65

Festkalender $4,23,28,62-64,81,83,110$, $125,128,157,159-60,209,259,310$, 392- 93

flamen perpetuus (siehe Kaiserkultpriester)

Fluchtafel 150, 196, 214, 220-23, 240, 251, 354

Flusspferd 278, 281

Franken $80,116,164,265$

Gazelle (siehe Antilope)

Gedicht $13,36,87,91,95,97,114,123-24$, $131,133,166-67,169,197,201,209,214-$ 16, 219, 237-38, 266, 268-69, 274-75, 282, 292, 285, 297, 299, 302-5, 310, 312, $318,353,356,365$

Gesang 26, 34, 48, 61, 177, 210, 291, 293, 295, 298, 305, 355, 364, 368, 371

Geschmack $3,162,207,211,227,253,258$, $263,285,288,351-52,359-360,363$, $375,379,393$

Giraffe 278-79

Graffito $20,42,118,150,172,216-17,223-$ 24, 240, 242, 275, 277, 292, 294, 314-15, $317,319,323,330,342,347,353,360$, $367,368,378,400$

Gymnasium 208, 262-63

Handel (siehe Wirtschaft)

Hase 267, 284

Heidnischer Kult $\quad 23,55,59-60,380-81$ 
Hippodrom (Konstantinopel) 13, 42-43, 72, $91,163,170-71,177-78,180-87,201$, $209,212,214,219,226,259-60,270-71$, 276, 281, 315, 381-82, 397

hippotrophoi 104, 139-40

Hirsch 250, 279, 399, 400

Holzbauten $13,80,159,164,277,317,361$

homeristai 293

honorati (siehe principales)

Hund 210, 264, 267-69, 272-73, 276, 284, 286

Hyäne 278

Hymnus (siehe Gesang)

Ikonographie $72,117,122,169,174,179,182-$ $83,186-87,193-205,218-19,226,341-$ $43,346-51$

Infamie $40,66,74-79,83,233,235,244$, $263,320,353,357-58$

Jagd $81,144,200,204,260-62,267,275$, $278,282-87,348,384$

Juden $17-18,28-29,43,46,105,186,249$, 317, 330, 381, 396

Kaiserkult

- allgemein 61, 175-80, 227, 360

- Priester 17, 81, 102, 114-15, 119-26, 157, 176, 231, 265

Kalenden $34,60-63,65,69,102,158,168$, $187-88,294,309,382,392$

Kirche (Gebäude) 52, 224, 287, 361, 387-88, 391, 394

Kitharöde 293, 299

Klerus $39-41,75,119,141,225-26,316$, $329,338,368-69,388$

Kolosseum 1, 82, 93, 94, 98, 129, 130, 163, $230-31,238-39,244-45,250,259$, $266-67,272,279-80,328,331,364$

kolymbethra 313, 362-67

Konsuln 73, 128, 130, 157, 187-89, 266, 271, 281

Kontorniat $72,83,168,174,197,199,214$, $217-18,232-33,243,252,274-75,280-$ $81,354,356$

Kosmologie 197, 260

Kranzfest 159

Krokodil 128, 272-73, 280, 364

kynegion $92-93,163,236,249,253,259$, $262,268,270$
Leopard $98,239,250,264,271-73,278-79$, 281, 381, 406

Libretto 293, 296, 301, 344, 352

Lieder (siehe Gesang)

Liturgie $72,85,88,103,114,133,135,146$, 153,326

Löwe $187,239,250,264,267,269,271-72$, $273-76,278-79,281,286,348,381$

Luchs 272, 279, 382

Lupercalien 129, 158

Maioumas $\quad 34,67,101-2,158-59,321,367$

Märtyrer $\quad 287,311,332,387,393$

Mischfinanzierung $88,99-101,104-7,113$, $139,142,146,150,154,320,377,384$

Mittelalter $1,370-72,374-75,381-82,391$ Mönch 36, 39, 40, 43, 245

monomacheion 93, 236, 249, 253, 262, 268

Musik $3,48,25-26,30,71,113,128,186-$ $87,258,293,295,317,327,338-39,359$, 379

Mythos 23, 33, 334, 339-46

Nacktheit $\quad 25,31,293,362-63$

Nashorn 278

Nika-Aufstand 151,181-82

Nike (siehe Victoria)

Obelisk $\quad 39,72,93,174,182-83,196$

Olympische Spiele $\quad 40-41,60,85,95,101$, 135, 142, 157, 297-98, 329

Orchestra $134,231,276,280,301,307,318$, $362,364-66$

Ostern 62-63, 65

Ostgoten $\quad 68,79,116,127,130,144,168,220$, $251,265-67,275,309-10,324,372-73$

paideia 18, 66, 200, 340-44

Panther 268, 274-76, 279, 286, 406

Papst $40,42,119,128-29,168,235,237$, $307,388,392$

parabolani 71, 246, 381

Perser 185-86, 259, 279

Phoenikarchie 85

pompa $36-37,121,170,177-78,231,302$, 371

Prätur 70, 99, 128, 157, 266, 279-80

principales $17,102-3,114-15,125,134,241$, 286, 389-90, 393

Procurator 110,131 
Prostituierte $25-26,31,66,74-75,77-78$, $85,102-3,237-239,244,362,369$

Provinziallandtag $70-72,85,114-16,118$, 132, 157, 176, 240, 249, 257

Quästur 70, 99, 128, 157, 239, 258, 266

Reh (siehe Hirsch)

Rennpferde $34-36,43,46,52,71,86-87$, $97,100,116-17,119,128,139-40,165-$ $66,169,171,189,194-202,204-7,213$, $217,219-20,223-23,225-26,228,273$

Rennstall 43, 52, 96-97, 100, 140, 161, 201, 204, 207

Repertoire

- Mimus 292-93, 318, 334, 348, 351, 367, 368

- Pantomimus 295, 339-40, 344-45, 348, 352

sacerdos provinciae (siehe Kaiserkultpriester)

Säkularisierung (siehe Entsakralisierung)

Senatoren $17,70-71,78,82,97,109,117$, $125-30,140,143,235,238,241,257,266$, 274, 328, 356, 390

Sitzinschrift $\quad 29,82,129,206,216,286,328-30$ sodalitates $122,240,274-75$

Stadium 162, 166, 169, 275, 277-78, 328

Stadtrat $17,38,43,60,85,91,100,102-5$, $113,119,121-22,124-26,131,133-39$, $141,144,159,225,240,257,286,312,316$, $326-27,356,366,385$

Statthalter $17,52,60,62,65,71-72,76-77$, $85,91,94-96,99-105,108,112,118$, $122,132,137,144-46,157-58,176,188$, 212, 240, 244, 268, 273, 275, 312-13, $320,322,327,332,353,377$

Statuen

- Kaiser 38, 75, 175-81, 183, 320-21, 323, 332

- Schauspieler $75,176,216,320,353-55$

- Rennfahrer 75, 176, 209, 214-16, 219

Stier 264, 272, 286, 342

Strauß 250

Studenten $66-67,206,221,236,316,329$, 356

Subventionierung (siehe Mischfinanzierung)

Syriarchie $85,249,257,268,275$
Tanz 14, 25, 31, 47-48, 139, 187, 210, 236, 258, 293-95, 297, 305-6, 315, 319, 323, $327,335-38,343-44,347,355,363,365$, $370-71,381,393$

Taufe $26-27,37,76,233,244,248,320,344$, $357,363,368$

Terminologie $2-3,13-14,58,93,114-15$, $133,166,170,209,232,237-40,256,291$, 295, 304, 360, 370-71

Tiger 264, 268, 271-72, 278-79, 281

Tragödie $\quad 296-300,309,344-45,349,351-$ 52

tribunus voluptatum $82,108-11,309-10$

Tyche $\quad 60-61,158,183,217-18,224,380$

Umbauten

- Theater 231, 252, 276, 301, 307, 313-14, $333,361,365-67$

- Stadium 276-77

Unruhen $8,24,42,67,110,147-48,158,180-$ 82, 199, 271 318, 320-22, 324, 364, 377

Vandalen $44,81,122-23,166,184,203,220$, 252, 267, 311, 372

Verbote $28-29,38-39,43,56,59-63,65-$ $68,75,77,85,98,136,173,176,221,229$, $234-35,245-48,269-71,273,305$, $320-21,338,344,371,377,380-81$

Vergesellschaftung $322,325,329,332-33$, $373-74$

Verstaatlichung $\quad 4,19,85-88,90,98-99$, $103,104,108,112,142-47,149-50,154$, $270-71,360,377$

Victoria $34,55-56,170-71,178-80,194-$ $95,226,252,261$

voluptates $2,47,56-57,63,65,68-73,82-$ $83,99,109-10,119,121,229,307,376$

Wassermimus $158,362-67$

Weihnachten $62-63,381$

Westgoten $79,119,165,307$

Wildesel 278, 381

Wildpferd 278

Wirtschaft $\quad 27,52,86-87,128,143-44,216$, $272-74$

Zeremonienbuch 111, 212

Zirkuspartei

- rot 161,171

- weiß 161, 171 